\title{
Integrated TRIZ-AHP support system for conceptual design
}

\begin{abstract}
Amid the fierce rising competition in the market, accelerating the problem solving and decision making process have become major issues in product design especially in conceptual design stage. For years, Theory of Inventive Problem Solving (TRIZ) has been extensively applied in problem solving. In this paper, Analytical Hierarchy Process (AHP) was proposed to strengthen three major steps in TRIZ methodology namely as problem definition, root cause identification and solution generation. The integration was then structured in the form of computer-based system. The integration, application and software in AHP and TRIZ method have been discussed in this paper. This proposed support system not only provided evidence that TRIZ methodologies improved by the support of AHP and also aided the designers in early design phase such as concept, process and material selection.
\end{abstract}

Keyword: AHP; Conceptual design; Support system; TRIZ 